\title{
Association between health literacy and risk of depressive symptoms among Chinese college students
}

\section{Zhongyu Ren ( $\square$ renzhongyu@swu.edu.cn )}

Southwest University https://orcid.org/0000-0002-7280-7669

Jianhua Cao

Nanning Normal University

Bing Cao

Southwest University

Shuang $E$

Chuzhou University

Jujiao Kuang

Institute for health and sport, victoria university

Research article

Keywords: Health literacy, Depressive symptoms, Chinese, College students

Posted Date: September 21st, 2021

DOI: https://doi.org/10.21203/rs.3.rs-898451/v1

License: (c) (1) This work is licensed under a Creative Commons Attribution 4.0 International License. Read Full License 


\section{Abstract \\ Background}

The association between health literacy and depressive symptoms has been examined among Chinese middle school students, however there is no evidence are available from college students.

\section{Aims}

This study aimed to examined the association between health literacy and depressive symptoms among Chinese college students.

\section{Methods}

This cross-sectional study recruited 2771 college students in Southwest University. Depressive symptoms was assessed using Zung self-rating depression scale and a score of $\geq 50$ represented having depressive symptoms. We used Chinese adolescent interactive health literacy questionnaire to assess health literacy. Multivariate logistic regressions analysis was applied to assess the association between health literacy and depressive symptoms.

\section{Results}

The prevalence of depressive symptoms was 34.9\% (967/2771). Multivariate logistic regressions analysis showed an inverse association between health literacy and depressive symptoms after adjusting for potential confounders. The multivariate adjusted ORs $(95 \% \mathrm{Cls})$ for depressive symptoms across quartiles of health literacy level were 1.000 (reference), $0.48(0.39,0.60), 0.25(0.19,0.32)$, and $0.16(0.12$, $0.21)$ ( $P$ for trend: $<0.001)$. Similar associations were also found when all 6 health literacy dimensions were analyzed separately.

\section{Conclusion}

The results of this cross-sectional study indicated that higher health literacy level was associated with lower risks of depressive symptoms. Further prospective studies or randomized controlled trials should be conducted to prove the causal association between health literacy and risk of depressive symptoms.

\section{Introduction}

Health literacy is defined as a ability that individual can obtain, understand and utilize health information and services, and make reasonable decisions in order to prevent diseases and promote health [1]. A 
abundant of studies indicated that health literacy level vary greatly in epidemiological investigation among different countries and population, and compared with developed countries from Europe and America, Asian population have a higher proportion of low health literacy. For example, Recent metaanalysis including European Union Member States showed that low health literacy account for 27-48\% among European [2]. Similarly, finding from American population-based meta-analysis reported that the prevalence of low health literacy was $26 \%$ [3]. However, the proportion of low health literacy was up to 55.3\% among Southeast population [4]. The China Health Literacy Survey also showed a lower level of health literacy that only $23.15 \%$ population had eligible health literacy among Chinese residents. Although health literacy level has steadily advanced, from $6.48 \%$ in 2009 [5] to $23.15 \%$ in 2020 [6], the Chinese government issued a "Healthy China Action Plan", one of which is to reach $30 \%$ or higher of eligible health literacy of Chinese residents by 2030 [7]. From these findings, we perceive a importance of promoting health literacy.

Given the priority of promoting health literacy is to reduce health risk behaviors, prevent diseases and promote health, many researchers conducted a series of studies aiming to explore associations between health literacy and health risk behaviors, non-communicable chronic diseases. On the one hand, a systematic review including 10,997 individuals in nine different countries concluded that intervention of health literacy is effective in changing health behaviors such as smoking behaviors, nutritional behaviors, physical activity behaviors and screening behaviors, etc [8]. On the other hand, several cross-sectional studies demonstrated that health literacy is not only associated with risk of physical disease, e.g., type 2 diabetes[9; 10], obstructive sleep apnea[11], obesity [12], but also beneficial to one's mental health. Recent several cross-sectional studies indicated that higher health literacy level was associated with lower risk of depressive symptoms among Chinese middle school students $[13 ; 14 ; 15]$. However, whether or not the above-mentioned association between health literacy and depressive symptoms also exists in Chinese college students remains unclear. According to results of the global burden of disease study, the prevalence of depression in young adolescents age 10-29 years was highest among all age group [16] and depression was leading cause for suicide [17]. In addition, approximately seventy-five percent of depression start from 24 years old in a lifetime [18], and it is therefore worthy to pay close attention to the association between health literacy and risk of depressive symptoms among college students in order to prevent developing depression early.

\section{Participants And Methods}

\section{Participants}

This study is a population-based cross-sectional study aiming to examine the association between health literacy and health status of college students college students studying in Southwest University (SWU), one of the largest university in Chongqing, Southwest China. SWU is a national key comprehensive university directly under the Ministry of Education and is co-developed by the Ministry of Agriculture and Rural Affairs and Chongqing Municipality. SWU has approximately 53000 full-time 
students and includes an extensive set of disciplinary categories: philosophy, economics, law, pedagogy, literature, history, science, engineering, agriculture, medicine, management, art, etc.

In March 2021, we recruited 2,893 participants who received an annual physical fitness assessment [BMI, lung function (forced vital capacity), $50 \mathrm{~m}$ sprint, sit and reach, standing long jump, 800/1000 m run, sit-ups/pull-ups)] at the physical fitness examination center of SWU. We asked all participants to complete a questionnaire including demographic variables (gender, age), health-related lifestyle factors (smoking and drinking status, sleep duration and quality) and depressive symptoms etc. We excluded participants with missing data on age $(n=7), B M I(n=54)$ and other data $(n=61)$. The final sample size after these exclusion was 2771 college students.

\section{Assessment of depressive symptoms}

We used Chinese version of Zung self-rating depression scale (SDS), which have been proved to have good reliability and validity [19]. The SDS consist of 20 items (10 positive items and 10 negative items) and each item have four options (none, a little of the time, most of the time, or all of the time). 10 positive items are assigned with one to four score, and 10 negative items are assigned with four to one score. The sum of the scores of all 20 items produce a total score of depressive symptoms, and participants with higher score of SDS reflected more severe depressive status. According to previous studies [20], this study defined SDS $\geqq 40$ points as having depressive symptoms. We used Cronbach's a coefficients to evaluate internal consistent reliability of the SDS, and this study showed that the Cronbach's a coefficients was 0.848 , demonstrating that the SDS has a a good internal consistent reliability.

\section{Assessment of health literacy}

Health literacy was assessed using the Chinese adolescent interactive health literacy questionnaire (CAIHLQ), which have been confirmed have good reliability and validity [21]. This scale is compose of 31 items and six dimensions including physical activity, interpersonal relationship, stress management, selfactualization, health awareness, dietary behavior. Each item was provided five options (never and no desire, never but with desire, occasionally and irregularly, often, and routinely). All 31 items are assigned with one to five score. We added up all items to produce a total score of health literacy and a higher score of health literacy reflected higher health literacy level. Cronbach's a coefficients (0.946) of this study confirmed that this scale had good internal consistent reliability.

\section{Assessment of covariates}

In addition to assessment of depressive symptoms and health literacy, all participants was also asked to complete a self-designed questionnaire. The questionnaire consists of demographic variables (gender, age), lifestyle factors [smoking and drinking status (regularly, occasionally, never), sleep duration (6-8 hours or not) and quality (good or bad)]. BMI was calculated by following formula: weight/(height) ${ }^{2}$.

\section{Statistical analysis}


All statistical analysis were performed using SPSS 24.0 (SPSS Inc., Chicago, IL, USA). For characteristics of study participants, continuous variables were expressed as geometric mean $(95 \% \mathrm{Cl})$ and categorical variables were expressed as proportion $(95 \% \mathrm{Cl})$. The differences of study participants characteristics between quartile group were compared using analysis of variance.

To examine the association between health literacy level and depressive symptoms, we applied multivariate logistic regressions analysis to analyze the association between health literacy quartiles and risk of depressive symptoms after adjustment for potential confounders. In Model 1, we adjusted for gender and age (continuous variable). Model 2 was further adjusted for lifestyle factors [smoking and drinking status (regularly, occasionally, never), sleep duration (6-8 hours or not) and quality (good or bad)] and BMI (continuous variable). $P<0.05$ was defined as having significant difference in all two-sided tests.

\section{Results}

Table 1 shows the participants' characteristics according to the categories of health literacy level. Individuals who had higher health literacy level were more likely to be female and older, lower proportions of occasionally smoking and 6-8 sleep duration, higher proportions of good sleep quality (All P for trend: $\leqq 0.025)$. However, we did not find the significant associations between health literacy level and other participants' characteristics. 
Table 1

Participants' characteristics according to categories of health literacy ${ }^{1}$

\begin{tabular}{|c|c|c|c|c|c|c|}
\hline$N=2771$ & Total & $\begin{array}{l}\text { Quartile } 1 \\
(n=690)\end{array}$ & $\begin{array}{l}\text { Quartile } 2 \\
(n=752)\end{array}$ & $\begin{array}{l}\text { Quartile } 3 \text { (n } \\
=642 \text { ) }\end{array}$ & $\begin{array}{l}\text { Quartile } 4 \text { (n } \\
=687 \text { ) }\end{array}$ & $\begin{array}{l}P \text { for } \\
\text { trend }{ }^{2}\end{array}$ \\
\hline $\begin{array}{l}\text { Mean } \pm \text { SD } \\
\text { (score) }\end{array}$ & $\begin{array}{l}101.8 \\
\pm 21.0\end{array}$ & $75.6 \pm 14.5$ & $95.9 \pm 3.7$ & $109.1 \pm 3.8$ & $127.7 \pm 9.7$ & - \\
\hline Sex (female), \% & 58.6 & $\begin{array}{l}55.9(52.3 \\
59.6)\end{array}$ & $\begin{array}{l}56.1(52.6 \\
59.6)\end{array}$ & $\begin{array}{l}62.8(59.0 \\
66.6)\end{array}$ & $\begin{array}{l}60.0(56.3 \\
63.7)\end{array}$ & 0.025 \\
\hline Age, years & $\begin{array}{l}19.1 \pm \\
1.0\end{array}$ & $\begin{array}{l}19.2(19.1, \\
19.3)\end{array}$ & $\begin{array}{l}19.1(19.0, \\
19.2)\end{array}$ & $\begin{array}{l}19.0(19.0 \\
19.1)\end{array}$ & $\begin{array}{l}19.0(18.9, \\
19.1)\end{array}$ & $<0.001$ \\
\hline $\mathrm{BMI}, \mathrm{Kg} / \mathrm{m}^{2}$ & $\begin{array}{l}21.4 \pm \\
3.5\end{array}$ & $\begin{array}{l}21.3(21.0 \\
21.5)\end{array}$ & $\begin{array}{l}21.2(21.0, \\
21.5)\end{array}$ & $\begin{array}{l}21.1(20.9, \\
21.4)\end{array}$ & $\begin{array}{l}21.1(20.8, \\
21.3)\end{array}$ & 0.249 \\
\hline \multicolumn{7}{|l|}{$\begin{array}{l}\text { Smoking } \\
\text { status, \% }\end{array}$} \\
\hline Occasionally & 3.3 & $4.1(2.7,5.4)$ & $2.9(1.6,4.2)$ & $3.1(1.7,4.5)$ & $3.2(1.9,4.5)$ & 0.436 \\
\hline Regularly & 1.1 & $1.9(1.1,2.7)$ & $\begin{array}{l}0.4(-0.3 \\
1.1)\end{array}$ & $1.4(0.6,2.2)$ & $0.7(0.0,1.5)$ & 0.162 \\
\hline \multicolumn{7}{|l|}{$\begin{array}{l}\text { Drinking } \\
\text { status, \% }\end{array}$} \\
\hline Occasionally & 46.6 & $\begin{array}{l}48.8(45.1 \\
52.6)\end{array}$ & $\begin{array}{l}50.8(47.2 \\
54.4)\end{array}$ & $\begin{array}{l}45.6(41.8 \\
49.5)\end{array}$ & $\begin{array}{l}40.8(37.0 \\
44.5)\end{array}$ & 0.001 \\
\hline Regularly & 1.1 & $1.4(0.7,2.2)$ & $\begin{array}{l}0.5(-0.2 \\
1.3)\end{array}$ & $1.1(0.3,1.9)$ & $1.5(0.7,2.2)$ & 0.747 \\
\hline $\begin{array}{l}\text { Sleep duration, } \\
\text { 6-8hour }\end{array}$ & 75.9 & $\begin{array}{l}79.1(75.9 \\
82.3)\end{array}$ & $\begin{array}{l}78.1(75.0, \\
81.1)\end{array}$ & $\begin{array}{l}76.9 \text { (73.6, } \\
80.2)\end{array}$ & $\begin{array}{l}69.1(66.0 \\
72.3)\end{array}$ & $<0.001$ \\
\hline $\begin{array}{l}\text { Sleep quality } \\
\text { (good), \% }\end{array}$ & 81.9 & $\begin{array}{l}69.1(66.3, \\
71.9)\end{array}$ & $\begin{array}{l}79.5(76.8, \\
82.2)\end{array}$ & $\begin{array}{l}88.5(85.6, \\
91.4)\end{array}$ & $\begin{array}{l}91.1(88.3, \\
93.9)\end{array}$ & $<0.001$ \\
\hline \multicolumn{7}{|c|}{$\mathrm{BMI}=$ body mass index } \\
\hline \multicolumn{7}{|c|}{$\begin{array}{l}1 \text { All continuous variables are were log-transformed and expressed as estimated geometric means } \\
(95 \% \mathrm{Cl}) \text { because the distribution of all continuous variables was abnormal. }\end{array}$} \\
\hline \multicolumn{7}{|c|}{ and categorical variables are expressed as percentages $(95 \% \mathrm{Cl})$. } \\
\hline
\end{tabular}

The prevalence of depressive symptoms was 34.9\% (967/2771). After adjusting for potential confounding factors including sex, age, BMI, smoking and drinking status, sleep duration and quality, health literacy level was inversely associated with the risk of depressive symptoms (Table 2). The 
multivariate adjusted ORs (95\% Cls) for depressive symptoms across quartiles of health literacy level were 1.000 (reference), $0.48(0.39,0.60), 0.25(0.19,0.32)$, and $0.16(0.12,0.21)$ ( $P$ for trend: $<0.001)$.

Table 2

Adjusted odds ratios $(95 \% \mathrm{Cl})$ of associations of health literacy with depressive symptoms.

\begin{tabular}{|c|c|c|c|}
\hline$N=2771$ & No. of depressive symptoms & Model $1^{\mathrm{a}}$ & Model $2^{b}$ \\
\hline Health literacy quartile & - & - & - \\
\hline Quartile $1(n=690)$ & 408 & 1.000 (reference) $^{c}$ & 1.000 (reference) \\
\hline Quartile 2 ( $n=752)$ & 295 & $0.45(0.36,0.55)$ & $0.48(0.39,0.60)$ \\
\hline Quartile $3(n=642)$ & 153 & $0.21(0.17,0.27)$ & $0.25(0.19,0.32)$ \\
\hline Quartile $4(n=687)$ & 111 & $0.13(0.10,0.17)$ & $0.16(0.12,0.21)$ \\
\hline$P$ for trend ${ }^{d}$ & - & $<0.001$ & $<0.001$ \\
\hline \multicolumn{4}{|c|}{ a Model 1 adjusted for gender, age (continuous variable). } \\
\hline \multicolumn{4}{|c|}{$\begin{array}{l}\text { b Model } 2 \text { adjusted for Model } 1+\text { smoking status (never, occasionally, or regularly), drinking status } \\
\text { (never, occasionally, or regularly), sleep quality (good or not), sleep duration ( } 6-8 \mathrm{~h} / \mathrm{d} \text { or }<6 \text { and }>8 \\
\text { h/d) and BMI (continuous variable) at baseline. }\end{array}$} \\
\hline \multicolumn{4}{|c|}{ d Adjusted data are expressed as odds ratio (95\% confidence intervals). } \\
\hline
\end{tabular}

\section{Discussion}

In this young population-based cross-sectional study, we examined the association between health literacy level and risk of depressive symptoms. The results showed that higher health literacy level was associated with a lower risk of depressive symptoms after adjusting for potential confounding factors. In addition, we also implemented a stratified analysis for all 6 health literacy dimensions and similar associations were also observed when all 6 health literacy dimensions were analyzed separately.

Results of this study support previous findings from fewer findings which showed an inverse association between health literacy and risk of depressive symptoms. For example, Several population-based studies abroad has reported the association between higher health literacy level and lower risk of depressive symptoms among healthy adults [22] and patients with heart failure [23] or detoxification treatment [24]. In recent years, Chinese researches also carried out a series of studies on association between health literacy level and risk of depressive symptoms and mainly concentrated in middle school students and found that these were inversely significant associations between health literacy level and risk of depressive symptoms $[13 ; 14 ; 15]$. Compared with previous studies, we can further expand the scope of the study which we implement for the first time the large-scale cross-sectional study aiming to examine 
the association between health literacy level and risk of depressive symptoms among Chinese college students.

Several mechanisms have been proposed to explain the lower risk of depressive symptoms with higher health literacy level. The first explanation is that cognitive load play a mediator roles in the effect of health literacy on information recall. According to limited capacity model of motivated mediated message processing, message processing consists of message encoding, storage and retrieval and these three subprocesses need cognitive capacity to be accomplished. However, limited human cognitive makes encoding information (e.g. reading a message and receiving meaning from its content) require much cognitive capacity, this will result in less capacity left for message storage and receive [25; 26]. In order to enrich empirical study for cognitive capacity mechanism, prior study also revealed that individuals with lower health literacy level need more cognitive capacity to process health information and subsequent results in less recall of information [26]. Another study also revealed a similar finding that individuals with lower health literacy level made greater effort in reading ability and less effort in seeking information [26;27]. Based on the above findings, this study indicated that individuals with higher health literacy level were more likely to make rational health decisions and seek information to prevent or relieve development of depressive symptoms that those with lower health literacy level. The second explanation is that healthy behaviors could mediate the association between health literacy and risk of depressive symptoms. In two large-scale cross-sectional studies, researchers examined associations between health literacy level and healthy behaviors among Chinese adolescents population and the results confirmed that higher health literacy level decreased risk of health risk behaviors (e.g. smoking status, drinking status and screen time) [28] and contributed to health-promoting behaviors (e.g. physical activity and nutrition) $[29 ; 30]$. Furthermore, the associations between healthy behaviors and risk of depressive symptoms has been well-established [31].

According to previous studies, several potential factors that confound the association between health literacy level and risk of depressive symptoms should be considered. For lifestyle factors, a series of meta-analyses including 49 articles indicated that sleep duration and quality was associated with depressive symptoms [32] and current study also shows that individuals who had higher health literacy level were more likely to have 6-8 sleep duration, higher proportions of good sleep quality (Table 1). Similarly, smoking and drinking status positively correlated with health literacy and depressive symptoms respectively [33;34]. The association between health literacy and depressive symptoms remained significant after adjustment for aforementioned lifestyle factors. Additionally, There are significant differences in health literacy level between sex and age among Chinese college students [35]. Furthermore, the prevalence of depressive symptoms in female college students was higher than male college students [36] and college students who were older were more likely to have depressive symptoms [37]. In multivariate logistic model, we also additionally adjusted for BMI because BMI could confound the association between health literacy level [12] and risk of depressive symptoms [38]. However, after additionally adjustment for demographic variables and BMI, there were still significant association between health literacy level and depressive symptoms, indicating that the association between health literacy and depressive symptoms is independent of lifestyle factors, demographic variables and BMI. 
This study also had several limitations. First, the cross-sectional study design did not allow us establish a causal association between health literacy level and depressive symptoms. Second, this study only recruited college students southwest university, future studies need to further examine the abovementioned findings with larger representative Chinese college students population. Third, application of SDS cannot diagnose whether these college students with depressive symptoms have clinical depression.

\section{Conclusions}

The results of this cross-sectional study indicated that higher health literacy level was associated with lower risks of depressive symptoms. Further prospective studies or randomized controlled trials should be used to prove the causal association between health literacy and risk of depressive symptoms.

\section{Declarations}

\section{Author contributions}

ZR: conceptualization and methodology. ZR, JC, BC, SE, JK: formal analysis. ZR: data curation. ZR, JC: writing-original draft preparation, review, and editing. All authors: have read and agreed to the published version of the manuscript.

\section{Funding}

This research was funded by the Fundamental Research Funds for the Central Universities (SWU1909734), and 111 project (B21036).

\section{Acknowledgments}

We like to thank Southwest University College students who agreed to participate and gave informed consent for analysis of their data. We would also like to thank our staff from the Southwest University for their dedicated work.

\section{Ethics approval and consent to participate}

Ethics approval was obtained from the Institutional Review Board of the College of Physical Education of Southwest University.

\section{Consent for publication}

All participants aged $\geq 16$ years or their primary guardians of participants aged $<16$ years agreed to participant in this study and signed informed consent forms.

\section{Availability of data and materials}


The datasets used and analyzed during the current study (transcript of the interviews) are not publicly available due to privacy related issues. Information on transcripts is available from the corresponding author on reasonable request.

\section{Competing interests}

The authors declare that they have no competing interests.

\section{References}

[1] K. Sorensen, S. Van den Broucke, J. Fullam, G. Doyle, J. Pelikan, Z. Slonska, H. Brand, and H.-E.C.H. Literacy, Health literacy and public health: A systematic review and integration of definitions and models. Bmc Public Health 12 (2012).

[2] V. Baccolini, A. Rosso, C. Di Paolo, C. Isonne, C. Salerno, G. Migliara, G.P. Prencipe, A. Massimi, C. Marzuillo, C. De Vito, P. Villari, and F. Romano, What is the Prevalence of Low Health Literacy in European Union Member States? A Systematic Review and Meta-analysis. Journal of General Internal Medicine 36 (2021) 753-761.

[3] M.K. Paasche-Orlow, R.M. Parker, J.A. Gazmararian, L.T. Nielsen-Bohlman, and R.R. Rudd, The prevalence of limited health literacy. Journal of General Internal Medicine 20 (2005) 175-184.

[4] R. Rajah, M.A.A. Hassali, and M.K. Murugiah, A systematic review of the prevalence of limited health literacy in Southeast Asian countries. Public Health 167 (2019) 8-15.

[5] X. Wen, Report on the First National Health Literacy Survey Among Chinese Residents. . Chinese Journal of Reproductive Health 21 (2010) 120.

[6] N.H.C.o.t.P.s.R.o. China, In 2020, the health literacy levels of Chinese residents rise to $23.15 \%$ [in Chinese], 2021.

[7] H.C.A.P.P. Committee, Healthy China Action plan (2019-2030), 2019.

[8] R. Walters, S.J. Leslie, R. Polson, T. Cusack, and T. Gorely, Establishing the efficacy of interventions to improve health literacy and health behaviours: a systematic review. Bmc Public Health 20 (2020).

[9] L. O'Meara, S.L. Williams, K. Ames, C. Lawson, S. Saluja, and C. Vandelanotte, Low Health Literacy Is Associated With Risk of Developing Type 2 Diabetes in a Nonclinical Population. Diabetes Educator 45 (2019) 431-441.

[10] D. Tajdar, D. Luhmann, R. Fertmann, T. Steinberg, H. van den Bussche, M. Scherer, and I. Schafer, Low health literacy is associated with higher risk of type 2 diabetes: a cross-sectional study in Germany. Bmc Public Health 21 (2021). 
[11] J.J. Li, S.L. Appleton, G.A. Wittert, A. Vakulin, R.D. McEvoy, N.A. Antic, and R.J. Adams, The Relationship between Functional Health Literacy and Obstructive Sleep Apnea and its Related Risk Factors and Comorbidities in a Population Cohort of Men. Sleep 37 (2014) 570-+.

[12] E. Toci, G. Burazeri, H. Kamberi, D. Toci, E. Roshi, N. Jerliu, A. Bregu, and H. Brand, Health literacy and body mass index: a population-based study in a South-Eastern European country. Journal of Public Health 43 (2021) 123-130.

[13] Y. Chengling, Y. Rong, W. Yuhui, X. Shaojun, and Z. Shichen, Interaction between health literacy and sleep quality on depressive symptoms among middle school students Chinese Journal of School Health 38 (2017) 1849-1852+1855.

[14] H. Qianqian, P. Yang, J. Feng, and W. Hong, Health literacy and depressive symptoms and their relationship in junior high school students in Chongqing. Acta Academiae Medicinae Militaris Tertiae 43 (2021) 670-675.

[15] J. Wang, R. Yang, D. Li, N. Hong, C. Wang, Y. Wan, S. Xu, F. Tao, and S. Zhang, Association of health literacy and screen time with depressive symptoms among middle school students. Wei sheng yan jiu = Journal of hygiene research 48 (2019) 765-771.

[16] H.A. Whiteford, L. Degenhardt, J. Rehm, A.J. Baxter, A.J. Ferrari, H.E. Erskine, F.J. Charlson, R.E. Norman, A.D. Flaxman, N. Johns, R. Burstein, C.J.L. Murray, and T. Vos, Global burden of disease attributable to mental and substance use disorders: findings from the Global Burden of Disease Study 2010. Lancet 382 (2013) 1575-1586.

[17] A.J. Ferrari, R.E. Norman, G. Freedman, A.J. Baxter, J.E. Pirkis, M.G. Harris, A. Page, E. Carnahan, L. Degenhardt, T. Vos, and H.A. Whiteford, The Burden Attributable to Mental and Substance Use Disorders as Risk Factors for Suicide: Findings from the Global Burden of Disease Study 2010. Plos One 9 (2014).

[18] R.C. Kessler, P. Berglund, O. Demler, R. Jin, and E.E. Walters, Lifetime prevalence and age-of-onset distributions' of DSM-IV disorders in the national comorbidity survey replication. Archives of General Psychiatry 62 (2005) 593-602.

[19] H. Peng, Y. Zhang, Y. Ji, W. Tang, Q. Li, and X. Yan, Analysis of reliability and validity of Chinese version of SDS scale in women of rural area. Shanghai Med Pharm J 14 (2013) 20-2.

[20] W.W.K. Zung, A SELF-RATING DEPRESSION SCALE. Archives of General Psychiatry 12 (1965) 63-70.

[21] S. ZHANG, Y. WAN, S. TAO, J. CHEN, and F. Tao, Reliability and construct validity of the Chinese Adolescent Interactive Health Literacy Questionnaire. Chinese Journal of School Health 35 (2014) 332336.

[22] T.G. Rhee, H.Y. Lee, N.K. Kim, G. Han, J. Lee, and K. Kim, Is Health Literacy Associated With Depressive Symptoms Among Korean Adults? Implications for Mental Health Nursing. Perspectives in 
Psychiatric Care 53 (2017) 234-242.

[23] H.J. Zou, Y.X. Chen, W.J. Fang, Y.T. Zhang, and X.Z. Fan, The mediation effect of health literacy between subjective social status and depressive symptoms in patients with heart failure. Journal of Psychosomatic Research 91 (2016) 33-39.

[24] A. Lincoln, M.K. Paasche-Orlow, D.M. Cheng, C. Lloyd-Travaglini, C. Caruso, R. Saitz, and J.H. Samet, Impact of health literacy on depressive symptoms and mental health-related: Quality of life among adults with addiction. Journal of General Internal Medicine 21 (2006) 818-822.

[25] A. Lang, The limited capacity model of mediated message processing. Journal of Communication 50 (2000) 46-70.

[26] C.S. Meppelink, E.G. Smit, N. Diviani, and J.C.M. Van Weert, Health Literacy and Online Health Information Processing: Unraveling the Underlying Mechanisms. Journal of Health Communication 21 (2016) 109-120.

[27] C. von Wagner, C. Semmler, A. Good, and J. Wardle, Health literacy and self-efficacy for participating in colorectal cancer screening: The role of information processing. Patient Education and Counseling 75 (2009) 352-357.

[28] R. Yang, D. Li, J. Hu, R. Tian, Y. Wan, F. Tao, J. Fang, and S. Zhang, Association between Health Literacy and Subgroups of Health Risk Behaviors among Chinese Adolescents in Six Cities: A Study Using Regression Mixture Modeling. International Journal of Environmental Research and Public Health 16 (2019).

[29] E.J. Bae, and J.Y. Yoon, Health Literacy as a Major Contributor to Health-Promoting Behaviors among Korean Teachers. International Journal of Environmental Research and Public Health 18 (2021).

[30] L.-C. Chang, Health literacy, self-reported status and health promoting behaviours for adolescents in Taiwan. Journal of Clinical Nursing 20 (2011) 190-196.

[31] X.W. Wang, A. Arafa, K.Y. Liu, E.S. Eshak, Y.H. Hu, and J.Y. Dong, Combined healthy lifestyle and depressive symptoms: a meta-analysis of observational studies. Journal of Affective Disorders 289 (2021) 144-150.

[32] V.S. O'Callaghan, B. Couvy-Duchesne, L.T. Strike, K.L. McMahon, E.M. Byrne, and M.J. Wright, A metaanalysis of the relationship between subjective sleep and depressive symptoms in adolescence. Sleep Medicine 79 (2021) 134-144.

[33] J.D. Li, H.X. Wang, M. Li, Q.Y. Shen, X.P. Li, Y.P. Zhang, J.L. Peng, X.M. Rong, and Y. Peng, Effect of alcohol use disorders and alcohol intake on the risk of subsequent depressive symptoms: a systematic review and meta-analysis of cohort studies. Addiction 115 (2020) 1224-1243. 
[34] T.M. Luger, J. Suls, and M.W. Vander Weg, How robust is the association between smoking and depression in adults? A meta-analysis using linear mixed-effects models. Addictive Behaviors 39 (2014) 1418-1429.

[35] G.P. Du, Y. He, W. Li, Q. Ni, R. Li, Y.Y. Liu, and P.M. Wei, Health literacy of college freshmen in jiangsu, China A 3-year longitudinal survey. Medicine 100 (2021).

[36] W. Luo, B.L. Zhong, and H.F.K. Chiu, Prevalence of depressive symptoms among Chinese university students amid the COVID-19 pandemic: a systematic review and meta-analysis. Epidemiology and Psychiatric Sciences 30 (2021).

[37] L. Chen, L. Wang, X.H. Qiu, X.X. Yang, Z.X. Qiao, Y.J. Yang, and Y. Liang, Depression among Chinese University Students: Prevalence and Socio-Demographic Correlates. Plos One 8 (2013).

[38] Y.Y. Zhang, and B.Z. Liu, Body weight perception and depressive symptoms in Chinese college students. Children and Youth Services Review 124 (2021).

\section{Figures}




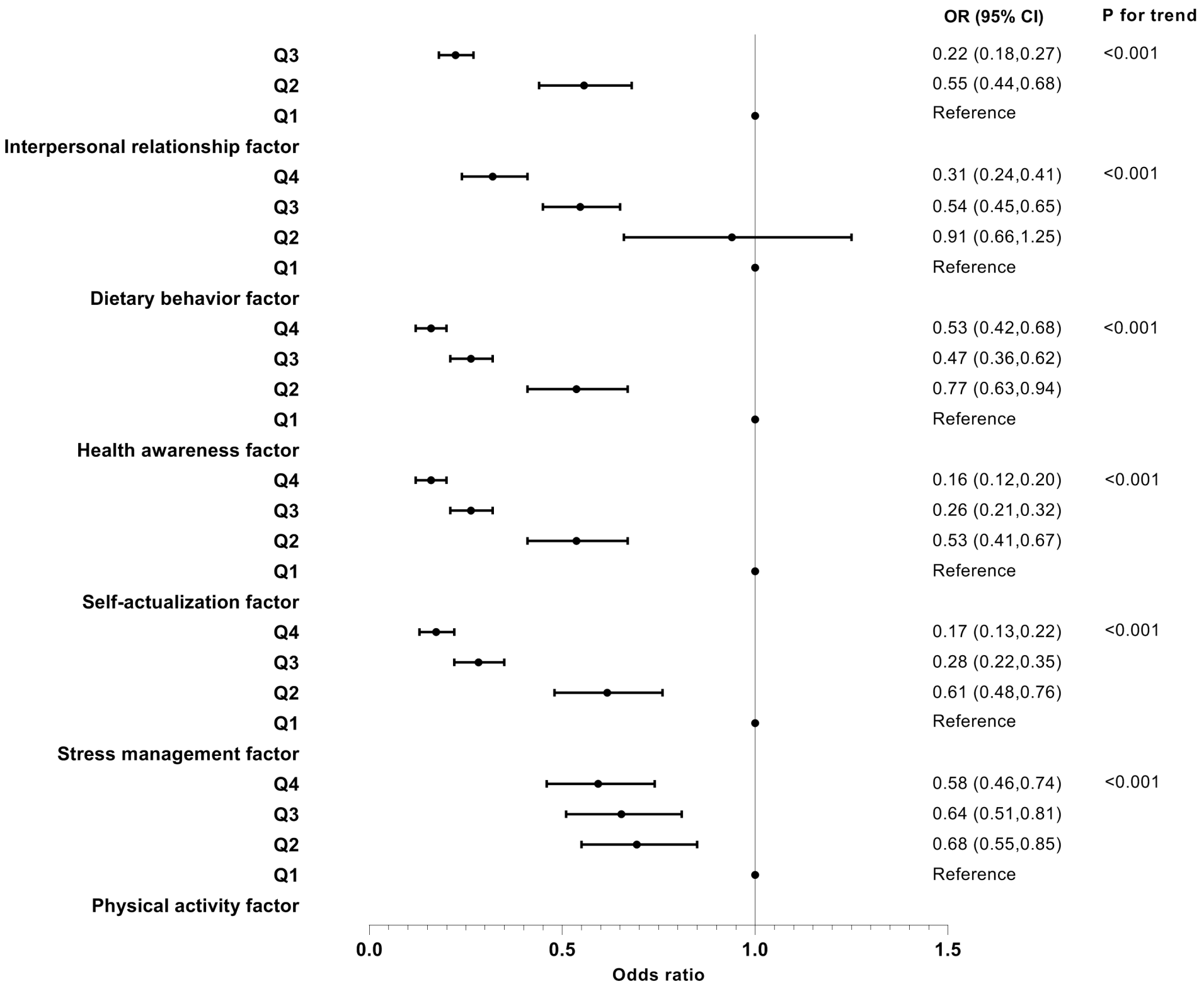

\section{Figure 1}

Forest plot of association between health literacy dimensions with depressive symptoms 